\title{
PURIFICACIÓN Y CARACTERIZACIÓN BIOQUÍMICA DE LA ENZIMA SIMILAR A TROMBINA DEL VENENO DE LA SERPIENTE Bothrops brazili
}

\author{
Luis Ruiz ${ }^{* a}$, Dan Vivas-Ruiz ${ }^{\mathrm{a}}$, Fanny Lazo ${ }^{\mathrm{a}}$, Wolfram Seiferta ${ }^{\mathrm{a}}$ Edith Rodríguez ${ }^{\mathrm{a}}$, \\ Gustavo Sandoval ${ }^{\mathrm{a}}$, Armando Yarlequéa.
}

\begin{abstract}
RESUMEN
Se ha purificado una enzima coagulante del veneno de la serpiente Bothrops brazili denominada enzima similar a trombina (TLE) mediante tres pasos cromatográficos sucesivos sobre Sephadex G-75, DEAE Sephadex A-50 y Sephadex G-50, empleando buffer Tris-HCl $0,05 \mathrm{M}$ pH 8,5. La enzima fue purificada 15,9 veces con un rendimiento del $28,6 \%$ y por PAGE-SDS se obtuvo una sola banda proteica de $48 \mathrm{kDa}$, tanto en condiciones reductoras como no reductoras usando $2 \beta$-Mercaptoetanol. Se trata de una proteína con actividad coagulante, tanto sobre plasma humano citratado como sobre fibrinógeno bovino. La enzima mostró actividad amidolítica sobre el sustrato cromogénico Benzoil-Arginil-p-Nitroanilina (BApNA) y la potencia coagulante sobre el fibrinógeno bovino fue calculada en 121 unidades $\mathrm{NIH}$ de trombina/mg. La enzima fue inhibida por PMSF y por el inhibidor de tripsina de soya, por lo que se trata de una serinoproteasa; el $\mathrm{pH}$ óptimo para la actividad amidolítica fue de 8,5 y la proteína fue estable al tratamiento térmico solo hasta los $40^{\circ} \mathrm{C}$. La dosis defibrinogenante mínima fue $8 \mu \mathrm{g} / \mathrm{g}$ de ratón y mediante pruebas de inmunodifusión doble se observó inmunorreactividad con respecto al suero antibotrópico polivalente del INS.
\end{abstract}

Palabras clave: Bothrops brazili, enzima similar a trombina, veneno, serpiente, coagulación.

\section{PURIFICATION, BIOCHEMICAL AND BIOLOGICAL CHARACTERIZATION OF THE THROMBIN-LIKE ENZYME PRESENT IN THE VENOM OFTHE SNAKE Bothrops brazili}

\begin{abstract}
A coagulant enzyme from Bothrops brazili snake venom called thrombin-like enzyme was purified by three successive chromatographic steps on Sephadex G-75, DEAE Sephadex A-50 and Sephadex G-50 using 0.05M Tris-HCl buffer $\mathrm{pH}$ 8.5. The enzyme was purified 15.9 times with a yield of $28.6 \%$ and by PAGE-SDS a single protein band of $48 \mathrm{kDa}$ was obtained both in reducing and non-reducing conditions using $2 \beta$-Mercaptoethano., It is a unicatenary
\end{abstract}

a Laboratorio de Biología Molecular, Facultad de Ciencias Biológicas. UNMSM.

*luiz27@outlook.com.pe 
protein with coagulant activity on both citrated human plasma and bovine fibrinogen. The enzyme showed amidolytic activity on the chromogenic substrate Benzoyl-Arginyl-pNitroaniline (BApNA) and the coagulant potency on bovine fibrinogen was calculated on $121 \mathrm{NIH}$ units of thrombin / mg. The enzyme was inhibited by PMSF and the soybean trypsin inhibitor, therefore, it is a serine protease; the optimum $\mathrm{pH}$ for the amidolytic activity was 8.5 and the protein was stable to heat treatment only up to $40{ }^{\circ} \mathrm{C}$. The minimal defibrinogenating dose was $8 \mu \mathrm{g} / \mathrm{g}$ of mouse and by double immunodiffusion tests immunoreactivity was observed with respect to INS polyvalent antibothropic serum.

Key words: Bothrops brazili, Thrombin-like enzyme, snake, venom, coagulation.

\section{INTRODUCCIÓN}

Los venenos de serpientes son una de las sustancias de mayor complejidad en el mundo animal, en estas se pueden encontrar una diversidad de moléculas orgánicas e inorgánicas que actúan de una manera sinérgica con el objetivo de inmovilizar, matar y digerir a la presa o, en caso alternativo, defenderse de sus depredadores. Los componentes orgánicos, en su mayoría, son de naturaleza proteica y entre estas destacan las serinoproteasas, un grupo particular de enzimas que poseen a un residuo de serina que dirige el ataque nucleofílico en la actividad catalítica.

Las serinoproteasas actúan principalmente a nivel sistema hemostático interfiriendo con los procesos de coagulación (activando o inhibiendo), procesos fibrinolíticos o sobre la agregación de plaquetas. En este grupo de proteasas destacan las enzimas similares a trombina o TLE (del inglés Thrombin-like enzymes) las cuales tienen la capacidad de coagular el fibrinógeno de una manera semejante a la trombina (enzima encargada de la coagulación sanguínea y otros procesos fisiológicos) $)^{1}$, no obstante, existen marcadas diferencias estructurales y funcionales entre las TLEs y la trombina, entre las que destacan la insensibilidad de las TLEs ante la heparina, principal inhibidor de la trombina y la no necesidad de iones para activar su catálisis.

Estructuralmente, las TLEs son monoméricas y presentan una triada catalítica compuesta por los residuos His 57, Asp 102 y Ser 195. Además, cuenta con seis puentes disulfuro encargados de la estabilidad, de los cuales cinco de ellos están presentes en todas las serinoproteasas, y el sexto (Cys91-Cys245) es exclusivo de las serinoproteasas de venenos de serpientes ${ }^{2}$.

Las TLEs son estudiadas por su potencial aplicación terapéutica como Reptilasa ${ }^{\circledR}$ y Ancrod de Bothrops atrox y Calloselasma rhodostoma, respectivamente, ambas empleadas para tratar afecciones cardiovasculares debido a la acción fisiológica coagulante in vivo que ejercen sobre el sistema hemostático.

En el Perú se ha realizado estudios rigurosos sobre esta enzima en los venenos de B. barnetti, B. pictus, B. atrox y L. muta ${ }^{3,4,5,6}$. En cuanto a Bothrops brazili, peruana, conocida también 
como “jergón shushupe”, solo se cuenta con un estudio preliminar de la TLE en su ponzoña, a partir de una purificación parcial y cuya actividad solo ha sido ensayada sobre sustratos cromogénicos ${ }^{7}$, sin embargo, la referencia más reciente con respecto a serinoproteasas de esta especie fue reportada por Zaqueo et al. ${ }^{8}$, quienes lograron purificar una de estas enzimas de un espécimen oriundo de Brasil. B. brazili es una especie particularmente abundante en la selva norte del Perú abarcando los departamentos de Loreto y Amazonas, frontera con Ecuador, y es una serpiente capaz de inocular hasta $4 \mathrm{~mL}$ de veneno por mordedura.

La importancia de este estudio estriba en conocer las características más relevantes de esta proteína coagulante y relacionarlas con el grado de toxicidad del veneno, su antigenicidad y la capacidad del antiveneno botrópico comercial para neutralizarla.

\section{PARTE EXPERIMENTAL}

\section{Veneno}

Se obtuvo veneno de especímenes adultos de Bothrops brazili procedentes de la zona del Alto Marañón, departamento de Amazonas, y mantenidos en el Serpentario "Oswaldo Meneses" del Museo de Historia Natural de la UNMSM. Posteriormente fue liofilizado y se mantuvo a $-20{ }^{\circ} \mathrm{C}$ hasta su uso.

\section{Cuantificación de proteínas}

La cantidad de proteína fue calculada midiendo la absorbancia de luz UV a $280 \mathrm{~nm}^{9}$ en un espectrofotómetro Genesys 5. Además, se empleó el método de Lowry ${ }^{10}$ modificado en nuestro laboratorio, utilizando un fotocolorímetro Spectronic Bausch \& Lomb, empleando albúmina sérica bovina como proteína estándar.

\section{Actividad coagulante}

Se realizó de acuerdo con el Manual del Instituto Clodomiro Picado ${ }^{11}$, usando como sustratos plasma humano citratado y fibrinógeno bovino comercial $(5 \mathrm{mg} / \mathrm{mL})$. El plasma humano se obtuvo de donantes voluntarios saludables, para ello se extrajo sangre venosa, la cual fue mezclada con solución de citrato de sodio 3,8 \% en relación $9: 1$ y se centrifugó a $4000 \mathrm{rpm}$ durante 10 minutos para separar el plasma de los paquetes globulares. El fibrinógeno bovino comercial fue preparado a una concentración de $5 \mathrm{mg} / \mathrm{mL}$ en buffer Tris $\mathrm{HCl} 0,05 \mathrm{M} \mathrm{pH} \mathrm{7,4}$ a $37^{\circ} \mathrm{C}$. La actividad consistió en preincubar $0,2 \mathrm{~mL}$ del sustrato a $37^{\circ} \mathrm{C}$ y posteriormente se adicionó $50 \mu \mathrm{L}$ de enzima purificada y se midió el tiempo de coagulación completa del sustrato. La actividad enzimática se determinó dividiendo la inversa del tiempo de coagulación entre los mg de proteína utilizados.

\section{Actividad amidolítica}

Se determinó empleando el método de Erlanger et al. ${ }^{12}$, utilizando el sustrato cromogénico Benzoil-Arginil-p-nitroanilida (BApNA) midiéndose la liberación de p-Nitroanilina por espectrofotometría. La mezcla de reacción contenía $1,5 \mathrm{~mL}$ de BApNA a una concentración de $9 \times 10^{-4} \mathrm{M} ; 0,5 \mathrm{~mL}$ de buffer Tris- $\mathrm{HCl} 0,05 \mathrm{M}$ pH 8,1 y $50 \mu \mathrm{L}$ de la muestra. Luego de 
incubar por 15 minutos a $37^{\circ} \mathrm{C}$ se adicionó $1 \mathrm{~mL}$ de ácido acético al $60 \%$ para detener la reacción y cuantificar la p-Nitroanilina por su absorbancia a $405 \mathrm{~nm}$.

\section{Purificación de la enzima}

$100 \mathrm{mg}$ de veneno de Bothrops brazili fueron disueltos en $1 \mathrm{~mL}$ de buffer Tris- $\mathrm{HCl}$ 0,05M $\mathrm{pH} 8,5$ y aplicados en una columna de filtración molecular Sephadex G-75 (28 x 1,2 cm) previamente equilibrada con buffer Tris- $\mathrm{HCl} 0,05 \mathrm{M} \mathrm{pH} 8,5$. Se colectaron fracciones de $1 \mathrm{~mL}$ a un flujo de $10 \mathrm{~mL} / \mathrm{h}$. Se determinó la cantidad de proteína en cada fracción por absorbancia a $280 \mathrm{~nm}$, el monitoreo de la enzima fue realizado por la actividad amidolítica y las fracciones con mayor actividad fueron juntadas, concentradas y aplicadas a una columna de DEAE Sephadex A-50 (30 cm x 1,5 cm). La enzima eluyó al aplicar el buffer ya mencionado con $\mathrm{NaCl} 0.3 \mathrm{M}$ a un flujo de $16 \mathrm{~mL} / \mathrm{h}$ y se monitoreó la actividad amidolítica. Las fracciones resultantes con mayor actividad fueron posteriormente recromatografiadas en una columna de Sephadex G-50 (28 x 1,2 cm) con buffer Tris- $\mathrm{HCl} 0,05 \mathrm{M} \mathrm{pH} \mathrm{8,5} \mathrm{a} \mathrm{un} \mathrm{flujo} \mathrm{de} \mathrm{9mL/h.}$ Finalmente, luego de evaluar la actividad amidolítica, se juntó y concentró las fracciones de interés para la evaluación del peso molecular.

\section{Electroforesis en geles de poliacrilamida con dodecil sulfato de sodio (PAGE-SDS)}

Cantidades equivalentes a $10 \mu \mathrm{g}$ de la enzima en estudio fueron tratadas con buffer muestra para PAGE-SDS en condiciones reductoras ( $\beta$-mercaptoetanol) y no reductoras usando una cámara vertical MINI-GEL System (Sigma), siguiendo la metodología de Laemmli13 . Se realizó la corrida electroforética en gel de poliacrilamida al $10 \%$ durante a $1 \mathrm{~h}$ a un voltaje constante de 120 voltios y se emplearon como proteínas patrones de peso molecular: albúmina sérica bovina (66 kDa), ovoalbúmina (45 kDa), anhidrasa carbónica (29 kDa) y lisozima $(14,3 \mathrm{kDa})$.

\section{Determinación de la potencia coagulante}

Se realizó empleando el método de Baughman ${ }^{14}$ usando fibrinógeno bovino comercial como sustrato, para comparar los tiempos de coagulación obtenidos con trombina bovina comercial (100 unidades), veneno total $(0,1 \mathrm{mg} / \mathrm{mL})$ y enzima purificada $(0,06 \mathrm{mg} / \mathrm{mL})$.

La acción coagulante de la trombina o de la enzima similar trombina se expresa en unidades $\mathrm{NIH}$ de trombina/mg de proteína. Se define una unidad como la cantidad de trombina capaz de coagular una muestra de $0,2 \mathrm{~mL}$ de plasma o fibrinógeno en un tiempo de 15 segundos a $37^{\circ} \mathrm{C}$.

\section{pH óptimo y efecto térmico}

El pH óptimo fue determinado empleando buffer acetato de sodio 0,2 $\mathrm{M}$ en un rango de 4,0 a 6,0; buffer fosfato de sodio $0,2 \mathrm{M} \mathrm{pH} \mathrm{6,0} \mathrm{-} \mathrm{7,0} \mathrm{y} \mathrm{buffer} \mathrm{Tris} \mathrm{HCl}$ 0,2M pH 8,0 - 10,0. Se midió la actividad sobre BApNA empleando $25 \mu \mathrm{L}$ de la enzima purificada. En cuanto al tratamiento térmico, alícuotas de $30 \mu \mathrm{L}$ de la enzima fueron sometidas a calentamiento por 15 minutos a temperaturas de $37,40,50,60,70,80$ y $90{ }^{\circ} \mathrm{C}$. Luego fueron enfriados rápidamente, colocándolos en hielo para inmediatamente después, medir la actividad sobre BApNA. 


\section{Efecto de iones metálicos e inhibidores}

Se prepararon preincubados de la enzima con los iones calcio, magnesio, sodio, potasio y manganeso bajo la forma de cloruros a concentraciones finales de 5 y $10 \mathrm{mM}$. El mismo tratamiento se empleó para ensayar los agentes: Fenil-metil sulfonil fluoruro (PMSF), Tosil lisil clorometil cetona (TLCK), Ácido Etilendiaminotetraacético (EDTA), iodoacetato e inhibidor de tripsina de soya, registrándose las actividades enzimáticas luego de estos tratamientos.

\section{Actividad Defibrin(ogen)ante}

Se determinó siguiendo el protocolo del Manual del Instituto Clodomiro Picado ${ }^{11}$, usando ratones albinos de la cepa Balb c obtenidos del Instituto Nacional de Salud (INS - Perú). La dosis defibrinogenante mínima (DDM) corresponde a la menor cantidad de veneno que produce incoagulabilidad total de la sangre en el lote correspondiente de ratones inyectados.

\section{Inmunodifusión}

Se evaluó siguiendo el método de Ouchterlony y Nilsson ${ }^{15}$. Para este ensayo se utilizó antiveneno botrópico polivalente (INS-Perú lote 1000376). Para el revelado se empleó azul brillante de Coomasie al 0,1 \% y solución decolorante para evidenciar las líneas de precipitación.

\section{RESULTADOS Y DISCUSIÓN}

\section{Purificación y peso molecular de la enzima}

En la figura 1 se resumen los pasos de purificación de la enzima similar a trombina del veneno de la serpiente $B$. brazili, nuestro procedimiento finalizó con la obtención de la proteína al estado homogéneo con un factor de purificación de 15,9 veces y un rendimiento de $28,5 \%$ (tabla 1). La proteína mostró un comportamiento básico a $\mathrm{pH} 8,5$ debido a que se ligó a la resina de DEAE y fue necesaria la adición del $\mathrm{NaCl}$ para desligarla. Los datos obtenidos reflejan ser más eficaces con respecto a lo reportado previamente por Limán? 

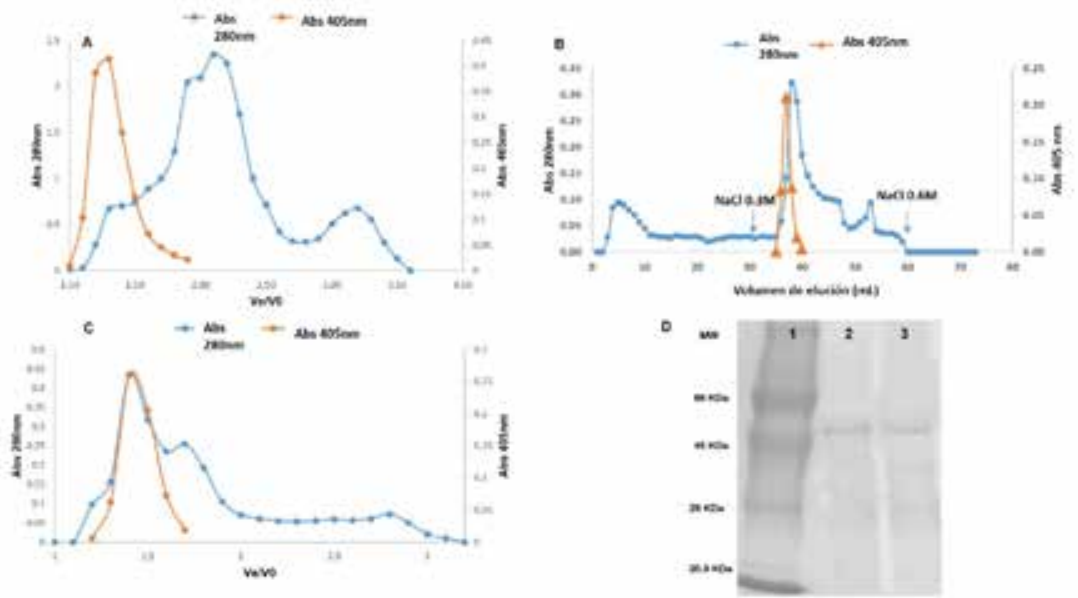

Figura 1. Purificación de la enzima similar a trombina de B. brazili. (A) Primer paso de purificación de la TLE sobre Sephadex G-75. (B) Segundo paso de purificación sobre DEAE Sephadex A-50. (C) Tercer paso purificación sobre Sephadex G-50. (D) Análisis en PAGESDS de la enzima purificada en condiciones reductoras (carril 2) y no reductoras (carril 3).

El análisis electroforético, tanto en condiciones reductoras como en no reductoras, mostró que la enzima purificada de $B$. brazili aparece como una banda de $48 \mathrm{kDa}$ calculado mediante la determinación del Rf (Fig. 1d), valor que se encuentra en el rango reportado para otras TLEs, que va desde los $29 \mathrm{kDa}$ hasta los $67 \mathrm{kDa}^{1}$ y que difiere de lo reportado por Zaqueo et $a l^{8}$ para una serinoproteasa aislada de la ponzoña de $B$. brazili de Brasil, donde se tuvo un peso molecular de $36 \mathrm{kDa}$ de masa relativa determinada por SDS-PAGE $12,5 \%$. La presencia de una única banda indica que la enzima purificada está compuesta de una sola banda proteica al igual que la mayoría de las TLEs ${ }^{1}$.

\section{Actividad similar a trombina}

El veneno total de B. brazili presentó una DCM-P de 18,32 $\mu$ g., mientras que para la misma especie Rojas ${ }^{16}$ obtuvo una DCM-P de 7,39 $\mu \mathrm{g}$. Esta variabilidad podría deberse a factores como la edad del ofidio, el hábitat, la dieta alimentaria y la estación en la cual se realizó la colecta del veneno. Casos similares se observan para el veneno total de Crotalus durissus y Lachesis muta, puesto que sus actividades coagulantes difieren según la zona geográfica ${ }^{17,18}$.

La actividad amidolítica de la enzima sobre BApNA $(0,317 \mathrm{U} / \mathrm{mg}$ de proteína) resulta menor que las exhibidas por otras enzimas purificadas de venenos de serpientes peruanas como Lachesis muta $(2,25 \mathrm{U} / \mathrm{mg})^{6}$, B. barnetti $(1,025 \mathrm{U} / \mathrm{mg})^{19}$, B. atrox, $(0,874 \mathrm{U} / \mathrm{mg})^{5}$ y B. pictus $(0,635 \mathrm{U} / \mathrm{mg} .)^{4}$. Sin embargo, y en contraste con lo reportado por Limán ${ }^{7}(0,074 \mathrm{U} / \mathrm{mg})$, la actividad específica de nuestra enzima purificada fue mucho mayor, debido también al mejor grado de purificación y rendimiento alcanzado con la metodología desarrollada en este estudio. 
Tabla 1. Cuadro de purificación de la enzima similar a trombina del veneno de Bothrops brazili.

\begin{tabular}{|c|c|c|c|c|c|c|}
\hline \multicolumn{7}{|c|}{ Tabla de purificación } \\
\hline \multirow[b]{2}{*}{ Muestra } & \multicolumn{2}{|c|}{ Protoina } & \multirow{2}{*}{$\begin{array}{l}\text { Actividad eapecifica } \\
\text { (Uimg) }\end{array}$} & \multirow{2}{*}{$\begin{array}{l}\text { Unidades } \\
\text { totalos do } \\
\text { actividad }\end{array}$} & \multirow[b]{2}{*}{ Pendimiento (\%) } & \multirow[b]{2}{*}{ Purificación } \\
\hline & Cantidad (mg) & $\%$ & & & & \\
\hline inidal & 100 & 100 & 0.02 & 2 & 100 & 1 \\
\hline $\begin{array}{c}\text { 1er paso } \\
\text { Sophadex G. } \\
75\end{array}$ & 8,3 & 8.3 & 0.18 & 1.46 & 73.0 & 8.8 \\
\hline $\begin{array}{c}200 \text { paso } \\
\text { DEAE } \\
\text { Sephadex A.50 }\end{array}$ & 2.6 & 2.6 & 0.19 & 0.50 & 25.1 & 9.7 \\
\hline $\begin{array}{c}\text { 3er pazo } \\
\text { Sophadax G- } \\
50\end{array}$ & 1.8 & 1,8 & 0.32 & 0.57 & 28.5 & 15.9 \\
\hline
\end{tabular}

\section{Potencia coagulante}

La potencia coagulante calculada para el veneno de B. brazili sobre el fibrinógeno bovino fue de 7,1 NIH de trombina/mg, mientras que para la enzima purificada fue de $121 \mathrm{NIH}$ de trombina/mg. La potencia coagulante de las TLEs purificadas están dentro de un rango de 0,03 a 2000 Unidades NIH de trombina/ mg de proteína y dentro del género Bothrops, el rango va de 0,7 a 1100 unidades $\mathrm{NIH}$ de trombina/mg $\mathrm{m}^{19,21}$.

\section{pH óptimo y termoestabilidad}

La mayoría de las TLEs son óptimamente activas a $\mathrm{pH}$ cercanos a 8,0 y son estables a $\mathrm{pH}$ neutros y alcalinos. La enzima aislada en este trabajo demostró tener una actividad por encima del $50 \%$ desde un pH neutro $(7,0)$ a moderadamente alcalino $(9,0)$, con un valor óptimo a pH 8,5 usando BApNA como sustrato. Este mismo valor fue obtenido para TLE de las serpientes peruanas $B$. pictus ${ }^{4}$ y B. barnetti ${ }^{19}$ y se asemeja a lo reportado para B. brazili de Brasil ${ }^{8}$.

El pH óptimo varía de acuerdo con la enzima y los diferentes sustratos sobre los cuales ellas actúan. Valores extremos de $\mathrm{pH}$ pueden causar desnaturalización proteica considerable y la consecuente inactivación enzimática, por eso es muy útil saber en qué rango de $\mathrm{pH}$ la enzima es más estable, ya que el pH de máxima estabilidad no siempre coincide con el de máxima actividad $^{3}$.

La enzima similar a trombina de $B$. brazili mostró una actividad enzimática creciente entre los 37 y $40{ }^{\circ} \mathrm{C}$, manteniendo más del $50 \%$ de su actividad hasta los $50{ }^{\circ} \mathrm{C}$ y registrando su acción máxima a $37^{\circ} \mathrm{C}$. Los resultados obtenidos se corroboran con los ya reportados por Limán ${ }^{7}$, donde la enzima de $B$. brazili presenta actividad máxima hasta los $40{ }^{\circ} \mathrm{C}$, pero pierde rápidamente su actividad llegando a tener solamente el $17 \%$ de actividad a los $70^{\circ} \mathrm{C}$. Estos resultados indican que la enzima de esta especie no es muy estable al tratamiento térmico (igualmente señalado por Zaqueo et al. ${ }^{8}$ ), a diferencia de las enzimas que poseen otras especies peruanas, como es el caso de $B$. pictus, cuya actividad amidolítica se mantiene por encima del $50 \%$ hasta los $90{ }^{\circ} \mathrm{C}^{4}$. La TLE de $B$. barnetti mostró óptima actividad amidolítica a $40{ }^{\circ} \mathrm{C}$ y mantuvo más del $50 \%$ de la misma hasta los $60^{\circ} \mathrm{C}^{19}$. En cuanto a la TLE del veneno de $L$. muta peruana presenta actividad en un rango de temperatura desde los $37^{\circ} \mathrm{C}$ a los 100 ${ }^{\circ} \mathrm{C}$, siendo la temperatura óptima para su actividad amidásica de $45^{\circ} \mathrm{C}^{6}$. 
De las dos propiedades bioquímicas anteriormente analizadas, se puede observar que la estabilidad frente al $\mathrm{pH}$ es la más resaltante en la enzima en estudio. Se conoce que la forma en como este estructurada una proteína le va permitir una cierta adaptabilidad a los medios en donde ejerce su acción catalizadora. Un claro ejemplo es el caso de las fosfolipasas A2 de las serpientes, particularmente por los puentes disulfuro que poseen (S-S) y por la termoestabilidad que estos les confieren a esas enzimas, permitiéndoles actuar a temperaturas de hasta $100{ }^{\circ} \mathrm{C}^{19}$.

Por otro lado, se ha llegado a establecer que la presencia de carbohidratos asociados a las TLEs les confiere no sólo la capacidad de una estabilidad térmica, sino también la estabilidad en ciertos rangos de $\mathrm{pH}^{3}$.
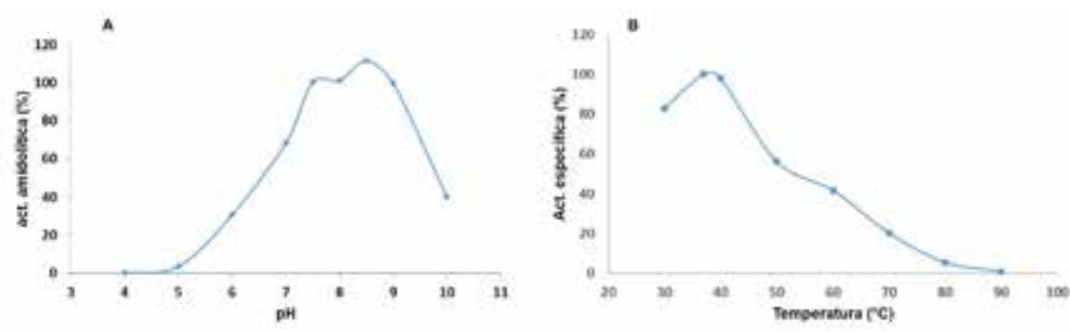

Figura 2. A) Determinación del pH óptimo para la actividad amidolítica de la enzima purificada. B) Efecto de la temperatura sobre la enzima purificada, evaluado en su actividad amidolítica.

\section{Efectos de iones metálicos e inhibidores enzimáticos}

En este estudio se observó que la enzima similar a trombina fue inhibida parcialmente por los iones $\mathrm{Mg}^{2+} \mathrm{y} \mathrm{Na}^{+}$a concentraciones de $10 \mathrm{mM}$ (9 y $31 \%$, respectivamente), mientras que el ión $\mathrm{Ca}^{+2}$ aumentó un $14 \%$ la actividad enzimática a una concentración de $10 \mathrm{mM}$ (tabla 2). El efecto de este último ion difiere de lo reportado previamente por $\operatorname{Liman}^{7}$, quien señaló que los iones $\mathrm{Ca}^{2+}$ producían una fuerte inhibición de la actividad de TLE de B. brazili. Por otro lado, Vivas et al., demostraron que el ion $\mathrm{Ca}^{2+}$ a $25 \mathrm{mM}$ no ejerce efecto alguno sobre la pictobina aislada de la serpiente peruana B. pictus. ${ }^{18}$ 
Tabla 2. Efecto de diversos iones metálicos sobre la enzima purificada.

\begin{tabular}{ccc}
\hline Ion & Concentración & Actividad (\%) \\
\hline control & $\cdot$ & 100 \\
\hline \multirow{2}{*}{$\mathrm{Ca}^{2+}$} & $5 \mathrm{mM}$ & 102.7 \\
& $10 \mathrm{mM}$ & 114.5 \\
\hline \multirow{2}{*}{$\mathrm{K}^{*}$} & $5 \mathrm{mM}$ & 101.8 \\
& $10 \mathrm{mM}$ & 103 \\
\hline \multirow{2}{*}{$\mathrm{Mg}^{2+}$} & $5 \mathrm{mM}$ & 100 \\
& $10 \mathrm{mM}$ & 91.4 \\
\hline \multirow{2}{*}{$\mathrm{Mn}^{2+}$} & $5 \mathrm{mM}$ & 102.6 \\
& $10 \mathrm{mM}$ & 103 \\
\hline \multirow{2}{*}{$\mathrm{Na}^{+}$} & $5 \mathrm{mM}$ & 90.7 \\
& $10 \mathrm{mM}$ & 69.5 \\
\hline
\end{tabular}

El uso de agentes químicos capaces de causar inhibición y/o modificación en diversos grupos funcionales que poseen las enzimas permitió elucidar detalles estructurales de la proteína en estudio. Se observó que la TLE tuvo una inhibición del $45 \%$ de su actividad con el PMSF, agente que fosforila al grupo hidroxilo del aminoácido serina presente en el sitio activo de las serinoproteasas, el mismo porcentaje de reducción que reporta Vivas ${ }^{17}$ para la actividad de la TLE de B. barnetti usando la misma concentración de este agente. En relación con lo obtenido, Limán ${ }^{7}$ reporta la inhibición del $47 \%$ de actividad enzimática de la TLE de $B$. brazili empleando una concentración de $1 \mathrm{mM}$ del agente.

Asimismo, el inhibidor de tripsina de soya (3 mg) inhibió en un $20 \%$ la actividad enzimática, esto debido al acoplamiento que realiza el inhibidor al bolsillo catalítico, región que es semejante en las enzimas de la familia génica tripsina/kalikreina a la cual también pertenece la trombina ${ }^{21}$.

Asimismo, no se detectó inhibición por la adición de EDTA $(5 \mathrm{mM})$, Iodoacetato $(5 \mathrm{mM})$ y TLCK (5mM) (tabla 3) indicando que la enzima no precisa de iones para su actividad, no posee residuos de cisteína libres y que no usa al residuo de histidina como agente nucleofílico, respectivamente. Estos resultados son semejantes para las TLEs de B. pictus ${ }^{4}, B$. brazili ${ }^{7}, B$. barnetti ${ }^{19}$ y Lachesis muta . $^{6}$ 
Tabla 3. Acción de inhibidores de proteasas sobre la proteína purificada

\begin{tabular}{ccc}
\hline Agente & Concentración final & Actividad (\%) \\
\hline Control & - & 100 \\
\hline PMSF & $5 \mathrm{mM}$ & 55.02 \\
\hline TLCK & $5 \mathrm{mM}$ & 101 \\
\hline $\begin{array}{c}\text { Inhibidor de tripsina de } \\
\text { soya }\end{array}$ & $3 \mathrm{mg} / \mathrm{mL}$ & 80.3 \\
\hline $\begin{array}{c}\text { Iodo acetato } \\
\text { EDTA }\end{array}$ & $5 \mathrm{mM}$ & 103.4 \\
\hline
\end{tabular}

\section{Dosis coagulante mínima (DCM) y acción defibrin(ogen)ante}

La Dosis Coagulante Mínima sobre plasma humano citratado (DCM-P) para el veneno fue de $18,3 \mu \mathrm{g}$, en tanto que para la enzima fue de 5,97 $\mu \mathrm{g}$. Por otro lado, usando fibrinógeno bovino comercial, los valores de la DCM-F fueron $60,3 \mu \mathrm{g}$ para el veneno y $26,4 \mu \mathrm{g}$ para la enzima purificada. Otros valores de DCM de TLEs de venenos peruanos nos muestran que la Barnetobina obtenida de B. barnetti tuvo una DCM-F de $0,9 \mu \mathrm{g}$ y una DCM-P de $1,1 \mu \mathrm{g}$, y para la Pictobina de $B$. pictus se tuvo valores de DCM-P $=18 \mu \mathrm{g}$ y DCM-F $=6 \mu \mathrm{g}$. En cuanto a la acción defibrin(ogen)ante empleando el modelo murino, se determinó una DDM de $8 \mu \mathrm{g}$ para la enzima purificada (tabla 4). Este valor resulta más elevado en comparación con los obtenidos para las enzimas purificadas de B. barnetti y B. pictus $(1 \mu \mathrm{g}$ y $1,2 \mu \mathrm{g}$, respectivamente) $)^{3,20}$

Tabla 4. Cuadro comparativo de la acción similar a trombina de la TLE purificada frente al veneno total.

\begin{tabular}{ccccc}
\hline Muestra & Activdad anidollica (U/mg) & DCM-P $(\mu g)$ & DCM-F $(\mu g)$ & DDM $(\mu g)$ \\
\hline Veneno tocal & 0.02 & 18.32 & 60.3 & n.d. \\
Enzima purificada & 0.32 & 5.97 & 26.35 & 8 \\
\hline
\end{tabular}

\section{Reactividad antigénica}

El veneno de $B$. brazili demostró ser reconocido, mediante inmunodifusión, por el suero antibotrópico polivalente producido por el Instituto Nacional de Salud, lo mismo ocurrió con la enzima purificada, por lo que se puede inferir que esta proteína promueva una respuesta inmune contra su estructura. Se tiene un reporte similar obtenido de la evaluación de la reactividad antigénica de las TLE de L. muta muta procedente de Perú y Brasil frente a un suero de origen equino producido por el Instituto Butantán de Brasil ${ }^{18}$. 


\section{CONCLUSIONES}

- El veneno de la serpiente Bothrops brazili posee una enzima similar a trombina con un peso molecular de $48 \mathrm{kDa}$.

- La enzima en estudio presenta actividad coagulante sobre plasma humano y sobre fibrinógeno bovino comercial con una potencia coagulante de $121 \mathrm{NIH} \mathrm{U/mg} \mathrm{de}$ trombina.

- La enzima tiene su mayor actividad en un rango de $\mathrm{pH}$ de 7,5 a 9,0 con un pH óptimo de 8,5 , y es termolábil.

- La enzima es una serionoproteinasa y no depende de iones metálicos.

- El antiveneno botrópico polivalente producido por el Instituto Nacional de Salud es capaz de reconocer antigénicamente a la enzima purificada.

\section{AGRADECIMIENTOS}

Los autores agradecen el financiamiento del programa FINCyT (ahora Innóvate Perú) Proyecto Contrato $N^{\circ}$ 131-FINCyT-IB-2013 "Producción de antivenenos específicos contra serpientes peruanas empleando tecnología IgY". El presente trabajo fue parte de la tesis de Licenciatura en Biología del autor principal.

\section{BIBLIOGRAFÍA}

1. Mackessy SP. Handbook of Venoms and Toxins of Reptiles. Boca Raton, FL: CRC Press; 2009.

2. Amiconi G, Amoresano A, Boumis G, Brancaccio A, De Cristofaro R, De Pascalis A, et al. A novel venombin B from Agkistrodon contortrix contortrix: evidence for recognition properties in the surface around the primary specificity pocket different from thrombin. Biochemistry. 2000; 39: 10294-10308.

3. Vivas-Ruiz D, Sandoval G, Mendoza J, Inga R, Gontijo S, Richardson M, et al. Coagulant thrombin-like enzyme (barnettobin) from Bothrops barnetti venom: molecular sequence analysis of its cDNA and biochemical properties. Biochimie. 2013; 95(7):1476-86.

4. Mesía M, Lazo F, Yarlequé A. Purificación y caracterización de un nuevo principio coagulante de la serpiente peruana Bothrops pictus. Rev Soc Quim Perú. 2011; 77(3):182-190.

5. Sandoval G, Ruiz N, Lazo F, Rodríguez E, Yarlequé A, Zingali R. Aislamiento y caracterización parcial de una enzima similar a trombina del veneno de la serpiente peruana Bothrops atrox "jergón". Rev Soc Quím Perú. 2010; 76(2): 156-164.

6. Yarlequé A, Campos S, Escobar E, Lazo F, Sánchez N, Hyslop S, et al. Isolation and characterization of fibrinogen-clotting enzyme from venom of the snake Lachesis muta. (Peruvian bushmaster). Toxicon. 1989; 27(11): 1189-1197.

7. Limán J. 1996. Purificación y caracterización parcial de la enzima similar a trombina del veneno de Bothrops brazili. [Tesis para optar al título profesional de biólogo con mención en genética]. Lima: UNMSM; 1996. 
8. Zaqueo KD, Kayano AM, Domingos TF, Moura LA, Fuly AL, da Silva SL, et al. BbrzSP-32, the first serine protease isolated from Bothrops brazili venom: Purification and characterization. Comp Biochem Physiol A Mol Integr Physiol. 2016; 195:15-25.

9. Warburg O, Christian W. Isolierung and Kristallisation der Garungs ferments enolase. Biochem Z. 1941; 310:384-421.

10. Lowry OH, Rosebrough NJ, Farr AL, Randall RJ. Protein measurement with the Folin phenol reagent. J Biol Chem. 1951; 193(1):265-75.

11. Instituto Clodomiro Picado. Determinación de actividades tóxicas de venenos de serpientes y su neutralización por antivenenos. Manual de Laboratorio. San José: Facultad de Microbiología. Universidad de Costa Rica; 2007. P. 21-22.

12. Erlanger B, Kokowsky N, Cohen W. The preparation and properties of two new chromogenic substrates of trypsin. Arch Biochem Biophys. 1961; 95: 271-278.

13. Laemmli U. Cleavage of structural proteins during the assembly of the head of bacteriophage T4. Nature. 1970; 227: 680-685.

14. Baughman DJ. Thrombin assay, In: Methods in enzymology, proteolitic enzymes. G.E. Periman \& L. Lorand Eds. New York-London: Academic Press. 1970: 145-157.

15. Ouchterlony $\mathrm{O}$, Nilsson L. Immunodifussion and immunoelectrophoresis. Handbook of Experimental immunology. 1967; I (34): 655- 660.

16. Rojas E, Quesada L, Arce V, Lomonte B, Rojas G, Gutiérrez JM. Neutralization of four Peruvian Bothrops sp. snake venoms by polivalent antivenoms produced in Peru and Costa Rica: preclinical assessment. Acta Trop., 2005; 93: 85-95.

17. Dos-Santos MC, Assis EB, Moreira T, Pinheiro J, Fortes-Dias C. Individual venom variability in Crotalus durissus ruruima snakes, a subspecies of Crotalus durissus from the Amazonian region. Toxicon. 2005; 46: 958-961.

18. Magalhaes A, Ferreira RN, Richardson M, Gontijo S, Yarleque A, Magalhaes HP, et al. Coagulant thrombin-like enzymes from the venoms of Brazilian and Peruvian bushmaster (Lachesis muta muta) snakes. Comp Biochem Physiol B Biochem Mol Biol. 2003; 136(2), 255-266.

19. Vivas Ruiz D, Inga Arellano R, Mendoza Fernández J, Lazo Manrique F, Yarlequé Chocas A. Barnetobina: Un nuevo principio coagulante purificado del veneno de la serpiente peruana Bothrops barnetti. Rev Soc Quím Perú. 2010; 76: 261-270.

20. Vivas-Ruiz D, Sandoval GA, Lazo F, Rodríguez E, Yarlequé A, Flores-Sánchez E. Caracterización de la enzima similar a trombina del veneno de Bothrops pictus "jergón de costa”. Rev Perú Med Exp Salud Pública. 2015; 32(4): 652-658.

21. Castro HC, Zingali RB, Albuquerque MG, Pujol-Luz M, Rodríguez CR. Snake venom thrombin-like enzymes: from reptilase to now. Cell Mol Life Sci. 2004; 61:843-856. 